\title{
. Construction of an expert-opinion-based virtual orebody for a diamondiferous linear beach deposit
}

\author{
by J. Jacob* and C. Prins ${ }^{\dagger}$
}

\section{Synopsis}

During early-stage diamond exploration projects, hard data underpinning spatial continuity is often very limited. An extreme example of this is a submerged diamondiferous marine placer target area alongside a current onshore mining area in southwestern Namibia. Although an abundance of geological and grade data exists for the adjacent onshore mining area, the target area itself contains no such information. Despite this apparent abundance of data, it is extremely difficult to obtain a variogram (Prins and Jacob, 2014) for use in this study area. The use of traditional simulation techniques is further hindered by the fact that diamond entrapment within the highly gullied footwall is non-stationary. An alternative approach for creating a simulated virtual orebody (VOB) is thus required in order to enable the assessment of sampling strategies.

This paper demonstrates how expert opinion is used to generate a composite probability map for diamond concentration using a greyscale hand-sketching technique. The probability map is subsequently calibrated and populated using the diamond distribution for different raised beaches obtained from analog data based on sample results adjacent to the target area. The resultant grade simulation is used to test different sample scenarios and is a first step towards determining an appropriate sampling strategy for the target area. The VOB is used to analyse and rank the efficiency of different sampling strategies for grade determination of submerged diamondiferous linear beach exploration targets.

Keywords

Expert opinion, simulation, diamondiferous marine placer, non-stationary.

\section{Introduction}

Expert opinion is used in various fields such as engineering, biological research, economics etc. (Kuhnert et al., 2009, Pearce et al., 2001) to assess uncertainty where limited or no hard data is available. Several approaches exist for combining probabilities obtained from expert opinion. The linear opinion pool (Stone, 1961; Winkler, 1968) is a weighted combination of expert opinion probabilities that satisfies the marginalization property. This requires that the combined probability is the same for combining either the marginal distributions or the joint distributions and then calculating the marginal distribution (Clemen and Winkler, 1999). Game theory is applied in deciding on when to combine which probabilities obtained from different methods that are equally appropriate based on the available data (Bickel, 2012).
A hierarchical modelling framework for combining expert opinion data and actual observed data for inferential purposes in a spatial context demonstrated that even a misleading expert opinion can be useful in cases where hard data refutes the expert opinion data (Lele and Das, 2000). The expert opinion data is influenced by hard data, hence the data-sets are not independent; for example, probabilities generated from different likelihood functions (Journel, 1986). Truong et al. (2014) illustrate how expert opinion is used as input to determine variogram parameters for downscaling from block support observations to point support where no point support observations are available.

Spatially, it is often very difficult to obtain or access hard data for a sampling optimization strategy. This paper demonstrates how expert geological opinion is firstly used to generate a composite probability map for diamond concentration using a greyscale hand-sketching technique; secondly, how the probability map is then calibrated to the correct sample support size; and thirdly, how the map is populated using the diamond grade distribution histogram obtained from observed analog data. Figure 1 shows the orientation and size of the virtual orebody (VOB) for a submerged diamondiferous marine placer target area in southwestern Namibia.

\section{Background}

Onshore diamondiferous linear beaches along the Namibian coast (Figure 1) have been the mainstay of Namdeb's diamond production for
* Namdeb Diamond Corporation.

$\dagger$ Anglo American plc.

(C) The Southern African Institute of Mining and Metallurgy, 2016. ISSN 2225-6253. This paper was first presented at, The Danie Krige Geostatistical Conference 2015, 19-20 August 2015, Crown Plaza, Rosebank. 


\section{Construction of an expert-opinion-based virtual orebody}

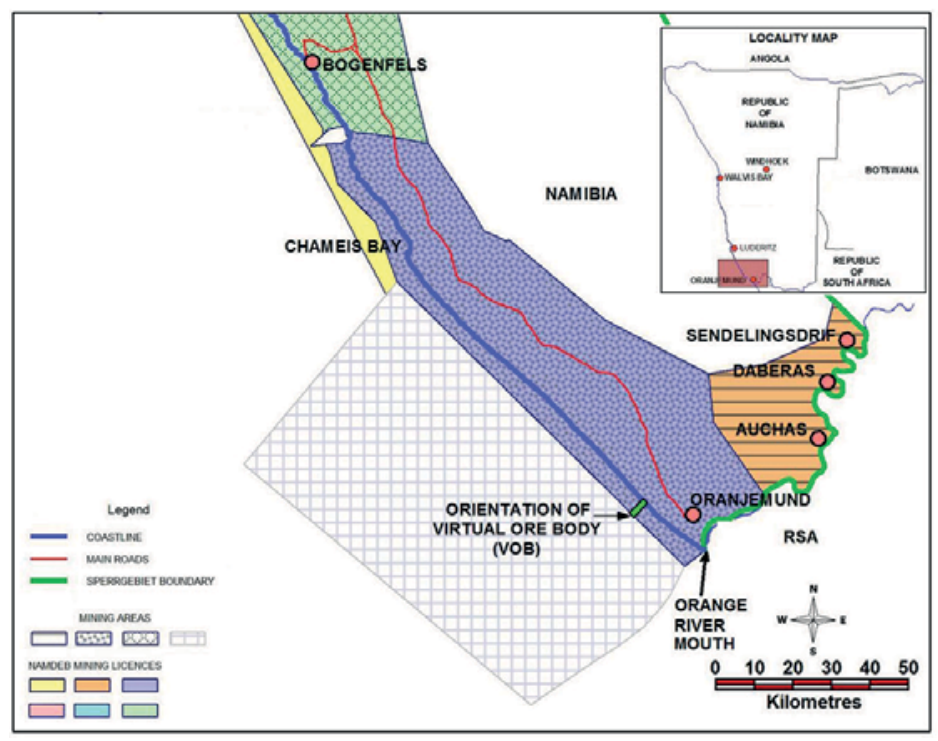

Figure 1-Locality map showing the size and orientation of the virtual orebody (VOB), southwestern Namibia

more than 80 years. These beaches are developed at different elevations, occurring as high as $30 \mathrm{~m}$ above sea level and as low as $30 \mathrm{~m}$ below sea level. A modern day analogue would be the present-day gravel beaches along the Black Sea in the Bolshoi Sochi region, which are perhaps good examples of what the study area's beaches would have looked like thousands of years ago (Spaggiari et al., 2006). The fossil gravel deposits of the study area extend continuously for approximately $100 \mathrm{~km}$ northward from the Orange River mouth along the coastline. Most of the onshore beaches have been mined out to date, but great potential exists in remaining areas that are currently submerged under water. During 2010, the concept of planned, controlled shoreline accretion was initiated; until then, accretion was a consequence of the stripping and dredging processes. Beach accretion is a natural process resulting from overabundance in sediment supply, which in effect builds the coastline outwards. The stripping and dredging processes are used to remove overburden sand in order to gain access to the diamondiferous basal marine gravel. At present, focused deliberate beach accretion is inherent in the mine plan and is also considered a possible means for mining of the submerged beaches. Therefore it is imperative to find a way to determine the diamond grade to justify the accretion for future mining areas.

The sea's high-energy swash zone makes obtaining upfront data well in advance of mining a challenge. In addition to the high-energy swash zone aerated water column, a sand overburden sequence must be penetrated before the diamondiferous basal gravel sequence is reached. At present, a probe drill platform (PDP) is the only implemented technology that successfully withstands these energies in the vigorous swash zone, and it provides geological data only. Furthermore, the sample size is too small for grade determination in the submerged target areas, due to the low-grade nature of the deposit (Jacob et al., 2013). The PDP is restricted by a land-bound base station and can operate only within $300 \mathrm{~m}$ from the current shoreline. The potential of the offshore linear beaches, however, extends up to $4 \mathrm{~km}$ seaward, and the challenge is thus to generate a VOB that can be used for sampling strategy and risk studies in the absence of any hard data.

\section{Nature of the analog data}

The initial delineation of the onshore raised beaches was done between the 1930s and 1960s by a comprehensive $1 \mathrm{~m}$ wide trench campaign. The $1 \mathrm{~m}$ trenches were spaced $500 \mathrm{~m}$ apart along the coast covering the $100 \mathrm{~km}$ from the Orange River mouth northwards to Chameis Bay (Figure 1). These 1 $\mathrm{m}$ trenches, orientated normal to the coastline, spanned six distinct onshore raised beaches. Continuous trench paddocks of $5 \mathrm{~m}$ lengths resulted in more than 26000 samples at $5 \mathrm{~m}^{2}$ support. Diamonds are concentrated in both gravel lenses (mobile trapsites) suspended above the bedrock footwall and in the highly gullied footwall. An example of the very detailed methodical mapping (1930s to 1960s) of the $1 \mathrm{~m}$ trench sections where the locations of individual diamonds are recorded is shown in Figure 2. The morphology of the marine erosion pattern on the bedrock surface (fixed trapsites) dominates the distribution of alluvial diamonds (Jacob et al., 2006). From detailed sampling results it is evident that twothirds of the diamonds occur in the fixed trapsites, with onethird in the mobile lenses; this observation is incorporated in the construction of the VOB.

\section{Methodology}

Prins (2011) developed a method using an expert opinionbased hand sketch to simulate the occurrence of diamonds in a VOB in cases where no hard data (spatial diamond grade) is available. The hand sketch is constructed on the principle that darker areas in the sketch represent areas with a higher probability of containing diamonds. This VOB is designed to form a strip connecting the current onshore area to the edge of the mining license approximately $4 \mathrm{~km}$ offshore (Figure 1 ). The methodology of developing the probability map based on 


\section{Construction of an expert-opinion-based virtual orebody}

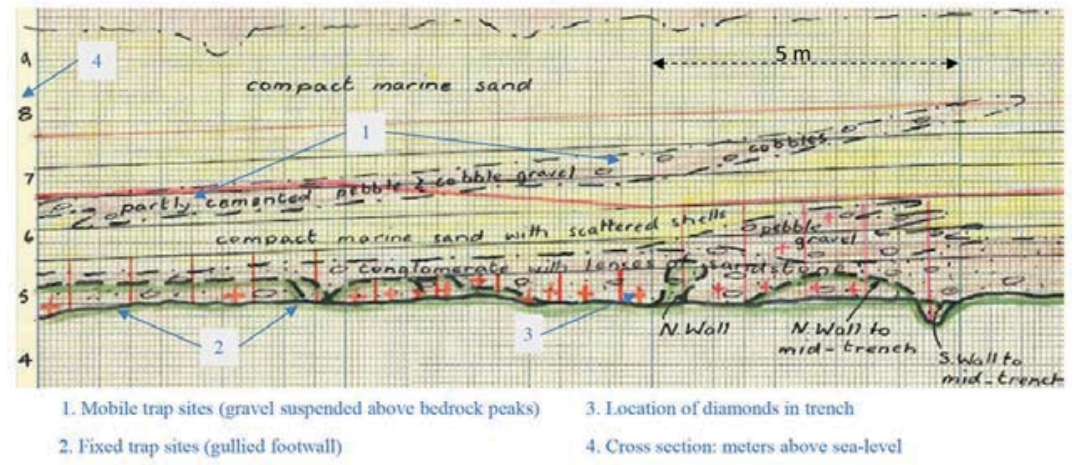

Figure 2-Vertical cross-section of a $1 \mathrm{~m}$ sample trench showing the spatial relation of fixed and mobile trapsites. Each sample paddock comprises a $5 \times 1$ $\mathrm{m}\left(5 \mathrm{~m}^{2}\right)$ support size

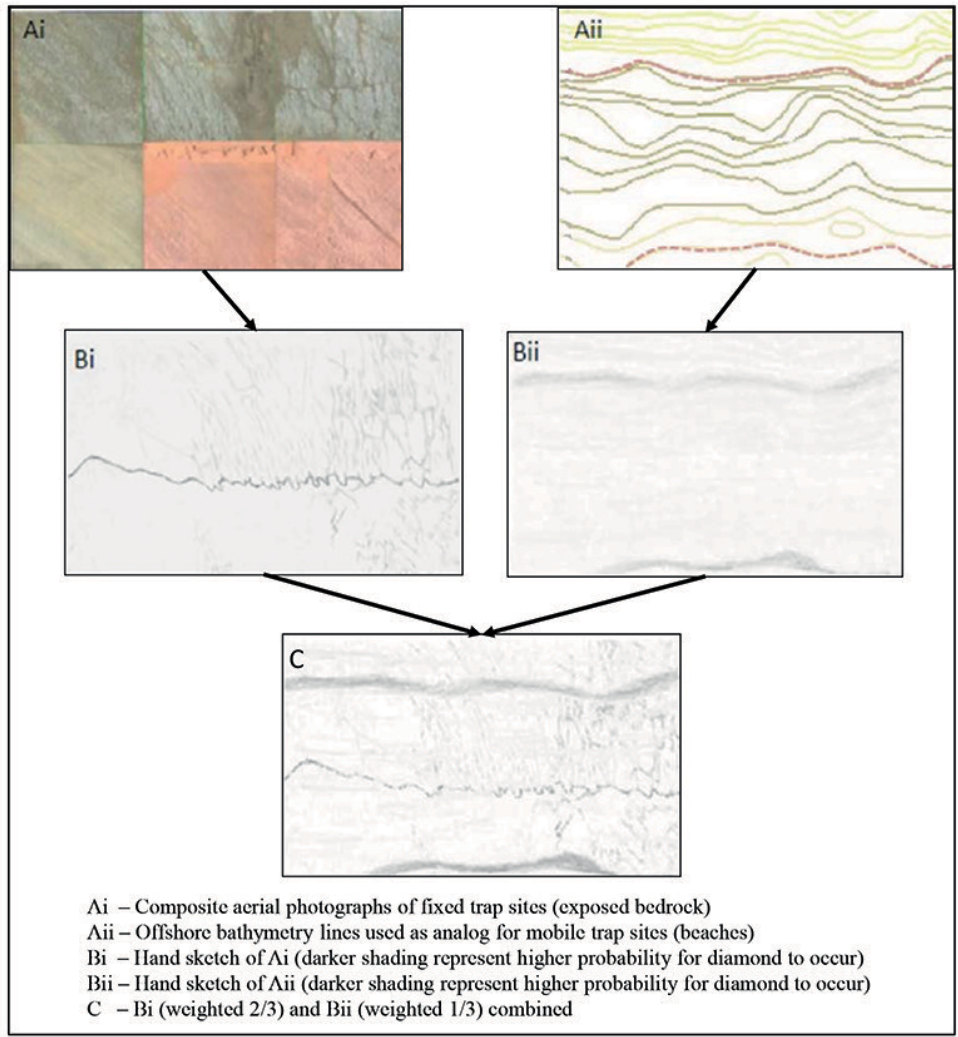

Figure 3-Steps involved in constructing a probability map for potential diamond entrapment

expert opinion is shown in Figure 3. The first step is the bedrock morphology sketch by the expert. The bedrock morphology is based on actual bedrock patterns currently exposed by onshore mining activities and exposed bedrock patterns obtained from bathymetry surveys in water depths greater than $30 \mathrm{~m}$. Secondly, sea-floor bathymetry contour lines are used as a proxy for gravel beach location suspended above the bedrock fixed trapsites. These two sketches are merged in such a way that the shading reflects the $2 / 3: 1 / 3$ proportion of diamond potential of the two trapsite types, resulting in a single combined probability model that can be used as a diamond potential entrapment map for the $1 \times$ $4 \mathrm{~km}$ strip.

Geologists with combined experience in the order of 50 years were asked to assess the resultant sketch after the merging described above. All agreed that the proposed model reflects current understanding of what could be a reasonable representation of diamond distribution in the study area, based on their extensive onshore production experience.

This paper introduces an additional aspect to the method proposed by Prins (2011), by applying the grade (stones per $\mathrm{m}^{2}$ ) profile observed across the different beaches, resulting in a grade-distance profile in the VOB (Figure 4). This profile is based on the average grade of the six onshore linear beaches obtained from the 26000 sample results spanning roughly $100 \mathrm{~km}$ from the Orange River mouth to Chameis Bay (Figure 1).

Statistical manipulation to align the hand sketch with the proxy grade data requires four steps. The first step is to regularize the sketch, mapped to scaled coordinates, into 


\section{Construction of an expert-opinion-based virtual orebody}

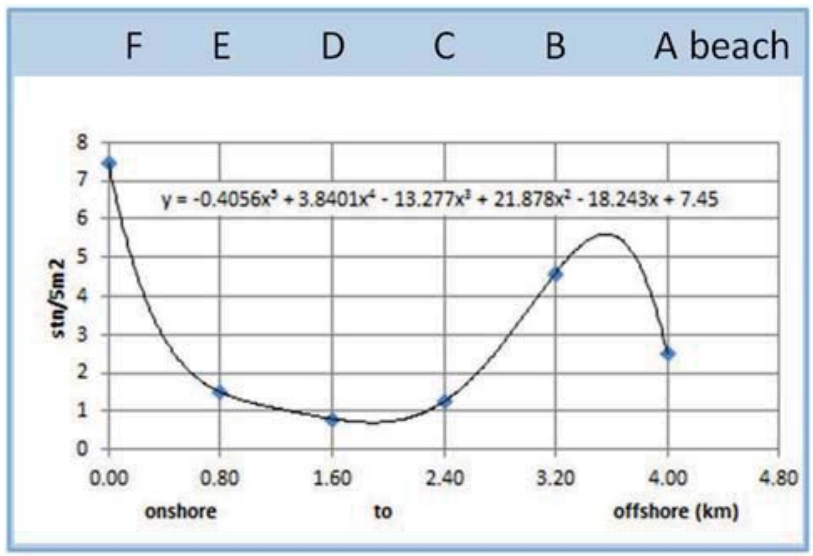

Figure 4-Grade profile used to adjust the diamond potential entrapment map

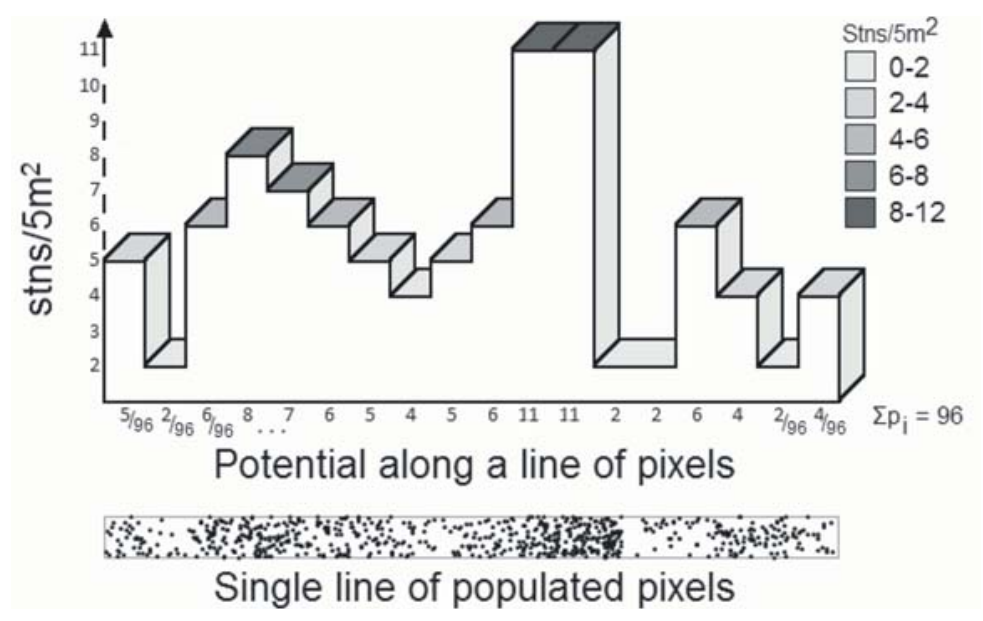

Figure 5-Diamond potential (greyscale), with a line of simulated stone locations

pixels representing $5 \mathrm{~m}^{2}$ data so that it is aligned with the support size of the proxy data. Secondly, a normal score transformation is applied to the potential obtained from the sketch. Thirdly, a back-transformation of the regularized sketch data is done using the distribution of the proxy data. Finally, a 5th-degree polynomial fitted to the grade in stones per $5 \mathrm{~m}^{2}$ per beach (Figure 4), with the y-axis as independent variable, is used to adjust the grade prior to seeding stones into the VOB. The grade-distance profile observed is thus matched to the grade-distance of the hand-sketched diamond entrapment potential map.

The outcome is finally adjusted by shifting the greyscale potential through histogram transformation, adjustment of individual histogram classes, and the random removal of stones (decimation). This is done in order to honour the zero proportions tail characteristics of the histogram, and univariate statistics of the proxy data.

Once the grade for a particular line of pixels is determined, the total number of stones for that line can be seeded. The individual stone locations simulated into the VOB based on the $5 \mathrm{~m}^{2}$ pixels' greyscale potential is shown in Figure 5. For example, the first pixel will have the potential to randomly receive 5/96th (the second pixel 2/96th, the third pixel 6/96th and so forth) of the number of stones for that line.

The process is graphically depicted in Figure 6, which shows how the two hand sketches are merged and the resulting $1 \times 4 \mathrm{~km}$ VOB. The three diagrams on the left-hand side in Figure 6 represent probability maps, while the righthand side diagram represents the locations of populated individual stones. Figure 7 (b, c, and d) is a zoomed-in version of the right-hand diagram in Figure 6, and individual dots representing the location of stones can be observed on this scale.

This simulation is one realization that is sampled, evaluated, and used to rank different sample spacing/size combinations to determine the optimum sampling strategy.

\section{Creating different grade scenarios using the VOB}

To create multiple realizations to facilitate decision-making for the exploration project, the hand sketch is also populated with the grade characteristics of individual beaches. This is done by regularizing the sketch to a sample support size of $5 \mathrm{~m}^{2}$ so that it is directly comparable to the support of the proxy sample data. A Gaussian transform of the potential 


\section{Construction of an expert-opinion-based virtual orebody}

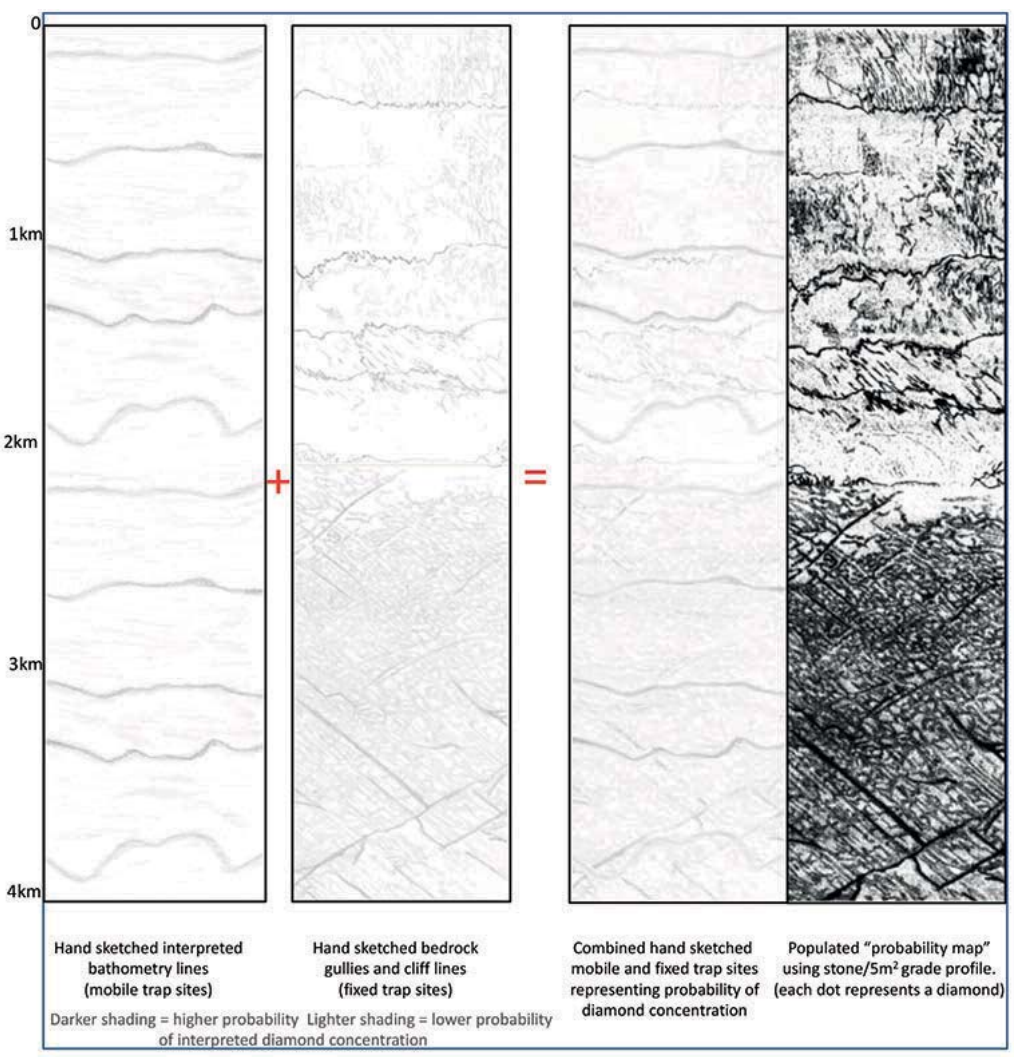

Figure 6-Process showing the combining of probability maps and grade profile to seed stones
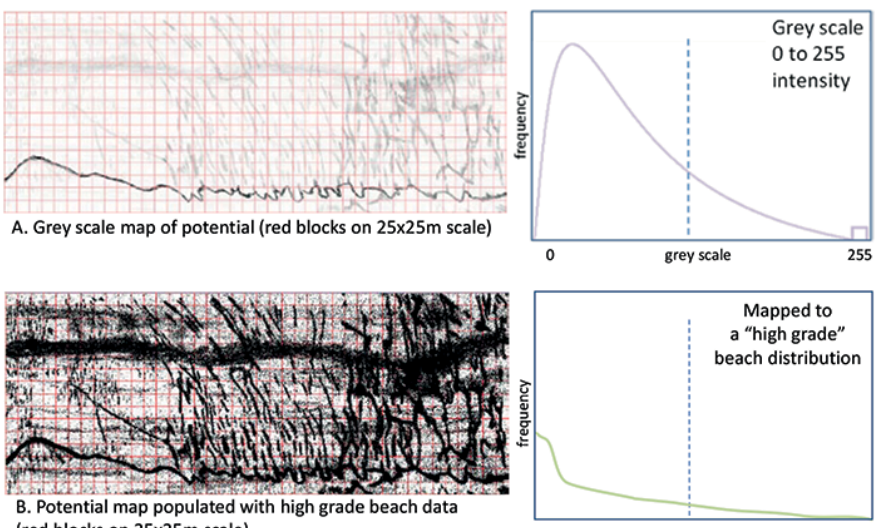

(red blocks on $25 \times 25 \mathrm{~m}$ scale)

stones per $5 \mathrm{~m} 2$
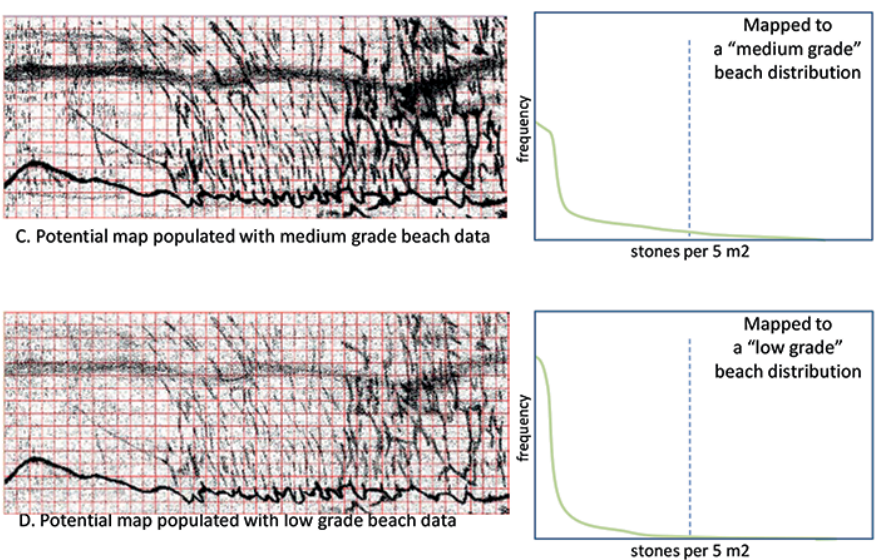

Figure 7-The simulated outcome for a $400 \times 1000 \mathrm{~m}$ portion of the study area, populated respectively by low, medium, and high (schematically presented) beach grades 


\section{Construction of an expert-opinion-based virtual orebody}

map is back-transformed using the transformation table of the proxy data. The underlying potential sketch remains unchanged but different results are obtained when backtransforming as the resultant realizations will have low, medium, and high grades with different higher order statistics (Figure 7).

In this way a range of possible outcomes is generated as realizations available for analysis. Since grade (the spatial intensity of the stones per unit area) affects the confidence of the resource estimates for a specific sample campaign, the realizations give an indication of the variability in the outcome of the assessments of the sample campaign effectiveness. The benefit of this work is that it can be used in risk rankings and assessments. Based on acceptable levels of uncertainty and taking into account the cost to execute a sampling campaign and the confidence obtained for the block estimates, the sampling scenarios can be ranked and a decision made on the appropriate course of action.

\section{Discussion and conclusions}

The authors admit to an acute awareness of the challenges of this approach. The quality of the hand sketch, paper texture, grey shading, and scan quality all impact on the final result of the VOB. In highly non-stationary environments where kriging is sometimes not possible, sample size and spacing are the most influential factors on the outcome of the final estimate. The VOB presented in this paper provides a first attempt at ranking different sampling scenarios. It also provides a preliminary risk quantification tool until such time when hard data becomes available for incorporation into conditional simulations. As data becomes available, the sample size and spacing should be re-assessed to confirm the outcome of the sketching technique, using well-established geostatistical simulation methods (Kleingeld et al., 1996) developed for discrete particles.

\section{Acknowledgements}

The authors would like to thank the De Beers, Anglo American, and Namdeb Mineral Resource Departments for their support, providing access to data, and permission to publish this work. The research presented in this paper forms part of a greater resource development project, also incorporated in a $\mathrm{PhD}$ study at the University of the Witwatersrand. The authors appreciate the comments and helpful suggestions from the reviewers.

\section{References}

BicKeL, D.R. 2012. Game-theory probability combination with applications to resolving conflicts between statistical methods. International Journal of Approximate Reasoning, vol. 53, no. 6. pp. 880-891.

Clemen, R.T. and WinkLeR, R.L. 1999. Combining probability distributions from experts in risk analysis. Risk Analysis, vol. 19, no. 2. pp. 187-203.

Cox, D.R. 1955. Some statistical methods connected with series of events (with discussion). Journal of the Royal Statistical Society Series B: Methodological, vol. 17, no. 2. pp. 129-164.

Jacob, J., Prins, C., and Oelofsen, A. 2013. Determination of sampling configuration for diamondiferous gravel occurrence using geostatistical methods - applied to a probe drill platform. Sampling and Analysis: Best Practise in African Mining, Misty Hills, Muldersdrift, 4-6 June 2013. Southern African Institute of Mining and Metallurgy, Johannesburg.

JacoB, J., WARD, J.D., Bluck, B.J., Scholz, R.A., and Frimmel, H.E. 2006. Some observations on diamondiferous bedrock gully trapsites on Late Cainzoic, marine-cut platforms of the Sperrgebiet, Namibia. Ore Geology Reviews, vol. 28 , no. 4. pp. 493-506.

JouRNEL, A.G. 1986. Constrained interpolation and qualitative information - the soft kriging approach. Mathematical Geology, vol. 18, no. 3. pp. 269-289.

JouRnEL, A.G. 1994. Modelling uncertainty: Some conceptual thoughts. Geostatistics for the Next Century. Dimitrakopoulos, R. (ed.). Kluwer, Dordrecht. pp. 30-43.

Kleingeld, W.J., Thurston, M.L., Prins, C.F., and Lantuéjoul, C. 1996. The conditional simulation of a Cox process with application to deposits with discrete particles. Proceedings of the Fifth International Geostatistical Congress, Geostatistics Wollongong '"96. Baafi, E.Y. and Schofield, N.A. (eds). Springer. pp. 638-694.

Kuhnert, P.M., Hayes, K., Martin, T.G., and McBride, M.F. 2009. Expert opinion in statistical models. Proceedings of the 18th World IMACS/MODSIM Congress, Cairns, Australia. Anderssen, R.S., Braddock, R.D., and Newham, L.T.H. Modelling and Simulation Society of Australia and New Zealand and International Association for Mathematics and Computers in Simulation. pp. 4262-4268.

LELE, S.R. and DAS, A. 2000. Elicited data and incorporation of expert opinion for statistical inference in spatial studies. Mathematical Geology, vol. 4. pp. $465-487$.

Pearce, J.L., Cherry, K., Dielsma, M., Ferrier, S., and Whish, G. 2001. Incorporating expert opinion and fine-scale vegetation mapping into statistical models of faunal distribution. Journal of Applied Ecology, vol. 38. pp. 412-424.

PRINS, C.F. 2011. Échantillonnage, simulation et estimation des gisements secondaires de diamante. PhD thesis, E.N.S des Mines de Paris.

PRINS, C.F. and ЈАСоB, J. 2014. Improved variography using simulated annealing to align sample locations within beach structures. Journal of the Southern African Institute of Mining and Metallurgy, vol. 114, no.3. pp. 251-254.

SpagGiari, R.I., Bluck, B.J., and WARD, J.D. 2006. Characteristics of diamondiferous Plio-Pleistocene littoral deposits within the palaeo-Orange River mouth, Namibia. Ore Geology Reviews, vol. 28. pp. 475-492.

Stone, M. 1961. The opinion pool. Annals of Mathematical Statistics, vol. 32. pp. 1339-1342.

Truong, P.N., Heuvelink, G.B., and Pebesma, E. 2014. Bayesian area-to-point kriging using expert knowledge as informative priors. International Journal of Applied Earth Observation and Geoinformation, vol. 30, no. 1. pp. 128-138.

WinkLER, R.L. 1968. The consensus of subjective probability distributions. Management Science, vol. 15, no.2. pp. 361-375. 